\title{
Prevalence and risk factor for intrauterine growth restriction among pregnancy-induced hypertension patient
}

\author{
Varuni Sharma ${ }^{1}$, Navin Shukla ${ }^{2 *}$ \\ ${ }^{1}$ Department of Obstetrics and Gynecology, ${ }^{2}$ Department of ENT, M. M. Institute of Medical Sciences and Research, \\ M.M Deemed to be University Mullana, Ambala, Haryana, India
}

Received: 17 May 2019

Accepted: 07 September 2019

*Correspondence:

Dr. Navin Shukla,

E-mail: drnavinshukla@yahoo.com

Copyright: $\odot$ the author(s), publisher and licensee Medip Academy. This is an open-access article distributed under the terms of the Creative Commons Attribution Non-Commercial License, which permits unrestricted non-commercial use, distribution, and reproduction in any medium, provided the original work is properly cited.

\begin{abstract}
Background: Hypertensive disorders in pregnancy (HDP) remain a major global health issue not only because of the associated high adverse maternal outcomes but there is a close accompaniment of significant perinatal morbidity. Intrauterine growth restriction (IUGR), a condition that occurs due to various reasons, is an important cause of fetal. It has been defined as a rate of fetal growth that is less than normal in light of the growth potential of that specific infant. The aim of this study is to evaluate the prevalence and risk factor for IUGR among the PIH patient.

Methods: A prospective randomized controlled clinical trial of 25 patients was carried out in Kamla Raja Hospital and Out Patient Department of Gajra Raja Medical College, Gwalior from October $6^{\text {th }}$ to October 2007. A total number of 25 patients were included in study of PIH.

Results: conclude that the prevalence and risk factor for IUGR among the PIH patient. The Distribution prevalence of sociodemographical factor for IUGR among PIH patient is statistically not significant. It concluded that there is no significance (no effect) between risk factors of IUGR among the pregnancy induced hypertension.

Conclusions: The prevalence of IUGR found in this study. There is need to increase awareness among medical and paramedical personnel on the need for early referral of women with previous history of IUGR, preeclampsia, multiple gestations, gestational diabetes and obesity for specialist care as they have a higher risk.
\end{abstract}

Keywords: Intrauterine growth restriction, Pregnancy-induced hypertension, Prevalence

\section{INTRODUCTION}

Pregnancy-induced hypertension (PIH), estimated to affect approximately $5 \%$ to $8 \%$ of pregnant women, is one of the main causes of maternal, fetal, or neonatal morbidity and mortality. ${ }^{1}$ PIH is classified into the following 3 categories: gestational hypertension, preeclampsia, and eclampsia. ${ }^{2}$ Hypertensive disorders in pregnancy (HDP) remain a major global health issue not only because of the associated high adverse maternal outcomes but there is a close accompaniment of significant perinatal morbidity. ${ }^{3}$ Intrauterine growth restriction (IUGR), a condition that occurs due to various reasons, is an important cause of fetal. It has been defined as a rate of fetal growth that is less than normal in light of the growth potential of that specific infant. Usually, IUGR and small for gestational age (SGA) are used interchangeably in literature, even though there exist minute differences between them. SGA has been defined as having birth weight less than two standard deviations below the mean or less than the $10^{\text {th }}$ percentile of a population-specific birth weight for specific gestational age. These infants have many acute neonatal problems that include perinatal asphyxia, hypothermia, 
hypoglycemia, and polycythemia. The likely long-term complications that is prone to develop when IUGR infants grow up includes growth retardation, major and subtle neurodevelopmental handicaps, and developmental origin of health and disease. In this review, we have covered various antenatal and postnatal aspects of IUGR. ${ }^{4}$ Intrauterine growth restriction is defined as the pathologic inhibition of intrauterine fetal growth and the failure of the fetus to achieve its growth potential5. Intrauterine growth restriction (IUGR) is a poorly understood complication of pregnancy, affecting up to $10 \%$ of live-born infants. It is characterized as a rate of fetal growth less than normal for the gestational-age appropriate growth potential. ${ }^{5}$ The mechanisms underlying IUGR are poorly understood, since there is much heterogeneity of disease etiology. In general, IUGR has been associated with 1 . fetal etiologies, such as genetic abnormalities (syndromes, chromosomal abnormalities), 2. maternal factors (vascular disease, persistent hypoxia or undernutrition, and toxins), and 3. placental etiologies. ${ }^{6}$ Intrauterine or fetal growth restriction (IUGR/FGR) is commonly recognized as an additional major risk factor for mortality and morbidity in very preterm infants. ${ }^{7}$ The complications of poor growth in utero are well described in term and near-term infants, and include hypoglycemia, polycythemia, temperature instability, and an increased risk of either asphyxia or fetal death. The literature has conflicting reports regarding morbidity and mortality in infants who are both preterm and IUGR. Several studies have found a decrease in the morbidity associated with prematurity when the infants are also poorly grown, suggesting an advantage to the stress of poor growth. ${ }^{8}$

The definition of IUGR contrasts with that for small-forgestational-age infants (SGA), who are typically defined as having birth weights below the $10^{\text {th }}$ percentile, though other definitions have been employed. Essentially, the definition of IUGR differs from SGA in that it refers to a pathophysiological process as opposed to a statistically derived definition. The differences in terminology and definitions has introduced heterogeneity into human studies. ${ }^{9}$ The fetal growth depends on various hormones, namely, insulin, thyroid, adrenal hormones, and pituitary hormones. These hormones promote the growth and development of the fetus and any disruption in these hormonal levels leads to IUGR. ${ }^{10}$ The causes of pregnancy-induced hypertension and the risk factors associated with it are largely unknown. Apart from null parity and previous history of preeclampsia in multiparas, few other risks are universally agreed upon. ${ }^{11}$ Placental insufficiency is the most common cause of IUGR where the nutrient transport to the fetus is compromised. ${ }^{12}$ Intrauterine growth restriction (IUGR) is the failure of the fetus to achieve its inherent growth potential and can be due to maternal or fetal problems. ${ }^{13}$

The aim of this study is to evaluate the prevalence and risk factor for IUGR among the PIH patient.

\section{METHODS}

A prospective randomized controlled clinical trial of 50 patients was carried out in Kamla Raja Hospital and Outpatient Department of Gajra Raja Medical College, Gwalior from October $6^{\text {th }}$ to October 2007. A total number of 50 patients were included in study. They were divided into 2 groups. Group A: Normotensive pregnant women - Control group and Group B: Antenatal patient with pregnancy induced hypertension - study group.

\section{Patients eligible criteria}

Pregnant women who attended outpatient department of obstetrics and gynecology or admitted in Kamla Raja Hospital, Gwalior and the patients who had completed 28 weeks of gestation which was calculated by absolute recall of her last menstrual period were included in the study. The pregnant women in their III $^{\text {rd }}$ trimester with single tone fetus were also included in the study whereas Patient in any of the group with medical disorder like jaundice, diabetes or any other systemic disorder were excluded from the study. In group A their blood pressure was within two different occasion 6 hours apart and proteinuria $>1+$ dipstick.

Patient included in the study group were subjected to the detailed history taking, through general and systemic examination and antenatal examination. Following investigations were sent-hemoglobin, urine (albumin and sugar) and serum homocysteine. For collecting blood samples, $3 \mathrm{ml}$ blood was withdrawn from vein by syringe and poured into a vial with full aseptic precautions. Vial was immediately kept in ice box. Samples were then transferred within one hour of collection to collecting centre for estimation of serum testosterone hormone levels. Method of direct chemiluminescence was used for estimating serum homocysteine levels in samples.

\section{Statistical analysis}

Data are presented by the help of PC using SPSS package. Statistical association were tested by chi square test, $\mathrm{p}$ value $<0.05$ was considered as statistically significant Fisher's test is applied for statistical analysis where Student t test is not applicable. Confidence interval (cl) was computed and adjusted odd ratio was computed for different risk factors.

\section{RESULTS}

Total 50 patients were included in study. The patients were divided into two groups, each consisting of 25 patients who were further classified into normotensive pregnant women (control group) and antenatal patient with pregnancy induced hypertension (study group).

The Table 1 shows distribution of cases in which 25 normotensive pregnant women taken as a control group and 25 patients with pregnancy induced hypertension as 
study group. Among the study group, out of 25 patients, $56 \%$ patients were below the age of 25 years, $60 \%$ of patients with pregnancy induced hypertension were illiterate and most of them had attended the hospital for first time after development of disease. Among the control group, out of 25 patients, $64 \%$ patients were below the age of 25 years, $36 \%$ patients were illiterate and most of them attended the hospital for the first time and the distribution of cases according to socio economic status shows that in control group out of 25 cases, no patients from the class I, $6(24 \%)$ from class II, 10 patients (40\%) from the class III and the 7 patients (28\%) from class IV and 2 patients ( $8 \%$ ) from class V whereas in $\mathrm{PIH}$ group of 25 cases, 1 patient from the class I, 4(16\%) from class II, $9(36 \%)$ from class III, 7(28\%) from class IV and $4(16 \%)$ cases from class $\mathrm{V}$. The distribution of the cases according to their residence shows that among the control group there $22(88 \%)$ cases from urban areas and $3(12 \%)$ cases from the rural areas whereas among the $\mathrm{PIH}$ group there were $18(72 \%)$ cases from urban areas and 7(28\%) cases from the rural areas. The distribution of cases according to parity shows that among the control group there were $12(48 \%)$ cases of Primigravida p0 group, $12(48 \%)$ of P1-P2 group and $1(4 \%)$ cases of P3-P4 group whereas among the PIH group there were $10(40 \%)$ cases of Primigravida p0, 14(56\%) cases of $1(4 \%)$ cases of P3-P4. There were 0 cases of P5 or more.

Table 1: Demographic distribution of patients.

\begin{tabular}{|c|c|c|c|}
\hline Variables & Categories & Control & PIH \\
\hline \multirow{2}{*}{ Age } & $\leq 25$ years & $16(64 \%)$ & $14(56 \%)$ \\
\hline & $>25$ years & $9(36 \%)$ & $11(44 \%)$ \\
\hline \multirow{5}{*}{ Education } & Nil & $9(36 \%)$ & $15(60 \%)$ \\
\hline & Primary & $3(12 \%)$ & $3(12 \%)$ \\
\hline & Middle & $4(16 \%)$ & $3(12 \%)$ \\
\hline & Higher secondary & $5(20 \%)$ & $1(4 \%)$ \\
\hline & Graduate & $4(16 \%)$ & $3(12 \%)$ \\
\hline \multirow{5}{*}{ Socio-economic status } & I & $0(0 \%)$ & $1(4 \%)$ \\
\hline & II & $6(24 \%)$ & $4(16 \%)$ \\
\hline & III & $10(40 \%)$ & $9(36 \%)$ \\
\hline & IV & $7(28 \%)$ & $7(28 \%)$ \\
\hline & $\mathrm{V}$ & $2(8 \%)$ & $4(16 \%)$ \\
\hline \multirow{2}{*}{ Residence } & Urban & $22(88 \%)$ & $18(72 \%)$ \\
\hline & Rural & $3(12 \%)$ & $7(28 \%)$ \\
\hline \multirow{4}{*}{ Parity } & Primigravida $\mathrm{p}_{0}$ & $12(48 \%)$ & $10(40 \%)$ \\
\hline & $\mathrm{P}_{1-} \mathrm{P}_{2}$ & $12(48 \%)$ & $14(56 \%)$ \\
\hline & $\mathrm{P}_{3}-\mathrm{P}_{4}$ & $1(4 \%)$ & $1(4 \%)$ \\
\hline & $\mathrm{P}_{5}$ or more & 0 & 0 \\
\hline
\end{tabular}

$*(\%)$ shows the percentage of the frequencies.

Table 2: Number of prevalence patient for IUGR among PIH.

\begin{tabular}{|llll|} 
& PIH & Control & $\mathrm{X}^{2}, \mathrm{p}$ value \\
IUGR present & 9 & 0 & $\mathrm{X}^{2}=2.000$ \\
IUGR absent & 16 & 25 & 0.157 \\
\hline
\end{tabular}

The Table 2 show the distribution IUGR present or absent in pregnant women taken as a control group and patients with pregnancy induced hypertension as study group. Among the control group 0 patient is present and 25 are absent or in PIH group 9 patient are present and 16 patient are absent. It is concluding that the $\mathrm{p}-0.157$ value is which is statistically insignificant.
The Table 3 shows that the distribution prevalence of sociodemographical factor for IUGR among 25 patients with pregnancy induced hypertension as study group. Among in study group 25 patients $<25$ age women out of 25. 5 patients are present IUGR and 9 patients are absent. The patient $>25$ age out of 25 patient 4 are present and 7 are absent. In education there are two category up to primary and more primary out of 25 patient 5 are having IUGR and 13 are absent then more to primary, 25 out of 4 patient are present 3 patient are absent in IUGR. Residency also divided into part urban and rural out 25 patients 6 are present in IUGR or 12 are absent in urban area but in rural 3 are present and 4 are absent patient in IUGR of study group. As in hemoglobin also divide into two $<10$ and $>10$ so out of 25 patient, 9 are present and 16 are absent in $<10$ and 0 are patient are present and 0 
are absent in $>10$ group of PIH study. Similarly in homocysteine level is in two category $<7.5$ and $>7.5$ out 25 patient 0 is present and 1 is absent in IUGR. p-Value, confidence and adjusted odd ratio is also evaluate of age, eduction, residence, hemogolobin and homocysteine level for IUGR among PIH patient. All p-value are $>0.05$ so it's statistically insignificant. Similarly in total IUGR present or absent. Among in total study group 50 patients $<25$ age women out of 50. 5 patients are present IUGR and 26 patients are absent. The patient $>25$ age out of 50 patient 4 are present and 15 are absent. In education there are two category up to primary and more primary out of 50 patients 5 are having IUGR and 26 are absent then more to primary, 50 out of 4 patients are present 15 patients are absent in IUGR. Residency also divided into part urban and rural out 50 patients 6 are present in IUGR or 34 are absent in urban area but in rural 3 are present and 7 are absent patient in IUGR of total study group. As in hemoglobin also divide into two $<10$ and $>10$ so out of 50 patients, 9 are present and 38 are absent in $<10$ and 0 are patient are present and 3 are absent in $>10$ group of Total study group. Similarly in homocysteine level is in two category $<7.5$ and $>7.5$ out 50 patient 0 is present and 14 are absent in $<7.5$ level and 9 present and 27 patient are absent in $>7.5$ level. Also p-value, confidence and adjusted odd ratio is also evaluate for IUGR among total patient. All p-values are $>0.05$ so it concludes that all factor are statistically insignificant.

Table 3: Distribution prevalence of sociodemographical factor for IUGR among PIH patient.

\begin{tabular}{|c|c|c|c|c|c|c|c|}
\hline \multicolumn{5}{|l|}{ PIH } & \multicolumn{3}{|l|}{ Total } \\
\hline Variable & IUGR P & & $\begin{array}{l}\text { IUGR } \\
\text { Absent }\end{array}$ & OR, CL, p-Value & $\begin{array}{l}\text { IUGR } \\
\text { Present }\end{array}$ & $\begin{array}{l}\text { IUGR } \\
\text { Absent }\end{array}$ & $\begin{array}{l}(\mathrm{Adj}) \mathrm{OR}, \mathrm{CL}, \\
\text { p-Value }\end{array}$ \\
\hline \multirow[b]{2}{*}{ Age } & $\leq 25$ & 5 & 9 & \multirow{2}{*}{$\begin{array}{l}0.97 \\
(0.1877-5.0346) \\
p=0.9732\end{array}$} & 9 & 26 & \multirow{2}{*}{$\begin{array}{l}0.7212(0.1674 \\
3.1063) \\
p=0.6608\end{array}$} \\
\hline & $\geq 25$ & 4 & 7 & & 4 & 15 & \\
\hline \multirow{2}{*}{ Education } & $\begin{array}{l}\text { Up to } \\
\text { primary }\end{array}$ & 5 & 13 & \multirow{2}{*}{$\begin{array}{l}0.288 \\
(0.04682-1.7766) \\
p=0.9732\end{array}$} & 5 & 26 & \multirow{2}{*}{$\begin{array}{l}0.7212 \quad 0.1674- \\
3.1063) \\
p=0.6608\end{array}$} \\
\hline & $\begin{array}{l}\text { More } \\
\text { primary }\end{array}$ & 4 & 3 & & 4 & 15 & \\
\hline \multirow[t]{2}{*}{ Residence } & Urban & 6 & 12 & \multirow{2}{*}{$\begin{array}{l}0.6667 \\
(0.1114-3.9899) \\
p=0.6569\end{array}$} & 6 & 34 & $\begin{array}{l}0.4118(0.0826 \\
2.0539)\end{array}$ \\
\hline & Rural & 3 & 4 & & 3 & 7 & $\mathrm{p}=0.2792$ \\
\hline \multirow[t]{2}{*}{ Hemogolobin } & $\leq 10$ & 9 & 16 & \multirow{2}{*}{$\begin{array}{l}0.5758 \\
(0.0105-31.4495) \\
p=0.7868\end{array}$} & 9 & 38 & $\begin{array}{l}0.7273(0.0820- \\
36.367)\end{array}$ \\
\hline & $\geq 10$ & 0 & 0 & & 0 & 3 & $\mathrm{p}=0.7252$ \\
\hline \multirow[t]{2}{*}{ Homocysteine level } & $\leq 7.5$ & 0 & 1 & \multirow{2}{*}{$\begin{array}{l}0.5439 \\
(0.0200-14.7600) \\
p=0.7176\end{array}$} & 0 & 14 & $\begin{array}{l}0.5439(0.0200- \\
14.7600)\end{array}$ \\
\hline & $\geq 7.5$ & 9 & 15 & & 9 & 27 & $\mathrm{p}=0.7176$ \\
\hline
\end{tabular}

\section{DISCUSSION}

Hypertensive disorder remains among the most important unsolved problems in obstetrics. Following three features characterizes preeclampsia/toxemia of pregnancy/PIHhypertension (BP>140/90), protein in urine and oedema. At present, the World Health Organization states that one in five women suffer from hypertension and almost half of mortality in women is caused by cardiovascular disease. ${ }^{14}$ This study is conducted prevalence of IUGR among 25 patients of pregnancy induced hypertension (PIH). The Table 1 show the demographical distribution of pregnancy induced hypertension patient; 25 patient of pregnancy induced hypertension as study group. Among the study group, out of 25 patients, $56 \%$ patients were below the age of 25 years, $60 \%$ of patients with pregnancy induced hypertension were illiterate and most of them had attended the hospital for first time after development of disease. In PIH group of 25 cases, 1 patient from the class I, $4(16 \%)$ from class II, $9(36 \%)$ from class III, 7(28\%) from class IV and 4(16\%) cases from class $\mathrm{V}$. The distribution of the cases according to their residence shows that the PIH groups there were $18(72 \%)$ cases from urban areas and $7(28 \%)$ cases from the rural areas. In another study conducted by Sachdeva et al, the incidence of PIH was found to be higher in rural women, though the difference was not significant. ${ }^{15}$ Second table shows that the distribution IUGR present or absent in pregnant women taken as a control group and patients with pregnancy induced hypertension as study group. Among the control group 0 patient is present and 25 are absent or in PIH group 9 patients are present and 16 patients are absent. Its concluded that the p-value is 0.002 which is statistically significant. Another study by Leung AS, Lynnae $\mathrm{K}$ et al, showed that gestational 
hypertension namely eclampsia, pre-eclampsia and PIH was significantly more common in the overt and subclinical hypothyroid patients than in general population with rates $22 \%, 15 \%$ and $7.6 \%$ respectively. In addition $36 \%$ of overt and $25 \%$ of the subclinical hypothyroid subjects who remained hypothyroid at delivery developed gestational hypertension. ${ }^{16}$ Table 3 shows the distribution prevalence of sociodemographical factor for IUGR among 25 patients with pregnancy induced hypertension as study group. Among in study group 25 patients $<25$ age women out of 25.5 patients are present IUGR and 9 patients are absent. The patient $>25$ age out of 25 patient 4 are present and 7 are absent. In education there are two category up to primary and more primary out of 25 patient 5 are having IUGR and 13 are absent then more to primary, 25 out of 4 patient are present 3 patient are absent in IUGR. Residency also divided into part urban and rural out 25 patients 6 are present in IUGR or 12 are absent in urban area but in rural 3 are present and 4 are absent patient in IUGR of study group. As in hemoglobin also divide into two $<10$ and $>10$ so out of 25 patient, 9 are present and 16 are absent in $<10$ and 0 are patient are present and 0 are absent in $>10$ group of PIH study. The prevalence of the hypertensive disorders in pregnancy $(17 \%)$ found in this study was similar to $21.6 \%$ and $17.2 \%$ that had been reported from south-eastern Nigeria and Finland. ${ }^{17}$ And the prevalence of IUGR in our institution during the study period was $24.9 \%$ which is comparable to study by Chauhan SP et al in which the prevalence of IUGR was observed to be $22 \% .^{18}$ In homocysteine level is in two category $<7.5$ and $>7.5$ out 25 patient 0 is present and 1 is absent in IUGR. P-value, confidence and adjusted odd ratio is also evaluate of age, eduction, residence, hemogolobin and homocysteine level for IUGR among $\mathrm{PIH}$ patient. All p-value are $>0.05$ so it's statistically insignificant. As in hemoglobin also divide into two $<10$ and $>10$ so out of 50 patient, 9 are present and 38 are absent in $<10$ and 0 are patient are present and 3 are absent in $>10$ group of Total study group. Similarly, in homocysteine level is in two category $<7.5$ and $>7.5$ out 50 patient 0 is present and 14 are absent in $<7.5$ level and 9 present and 27 patient are absent in $>7.5$ level. Also pvalue, confidence and adjusted odd ratio is also evaluate of age, eduction, residence, hemogolobin and homocysteine level for IUGR among total patient. All pvalues are $>0.05$ so it concludes that all factor are statistically insignificant. In Lindbald et al, studied Folate, Vitamin B12, and homocysteine levels in South Asian women with growth-retarded fetuses and observed that the youngest women, 22 years of age, had the highest homocysteine levels and the greatest risk of IUGR (OR, $2.9 ; 95 \%$ CI, 1.1-8.2) compared with the older women. ${ }^{19}$

\section{CONCLUSION}

In the present study, we conclude that the prevalence and risk factor for IUGR among the PIH patient. The distribution prevalence of sociodemographical factor for IUGR among PIH patient are statistically not significant.
It concluded that there is no significance between risk factors of IUGR among the pregnancy induced hypertension. There is need to increase awareness among medical and paramedical personnel on the need for early referral of women with previous history of IUGR, preeclampsia, multiple gestations, gestational diabetes and obesity for specialist care as they have a higher risk. Single mothers should be given special consideration and provided with social and economic welfare as these interventions may reduce their risk of developing hyper disorder of pregnancy (HDP).

Funding: No funding sources

Conflict of interest: None declared

Ethical approval: The study was approved by the Institutional Ethics Committee

\section{REFERENCES}

1. Xiong X, Fraser WD. Impact of pregnancy-induced hypertension on birth weight by gestational age. Paediatr Perin Epidemio. 2004;18:186-91.

2. Somerset DJ. Diagnosis, evaluation, and management of the hypertensive disorders of pregnancy: executive summary. Obstet Gynaecol Can. 2014;36(7):57

3. PubMedDuley L. The global impact of pre-eclampsia and eclampsia. Semin Perinatol. 2009;33:130-7.

4. Battaglia FC, Lubchenco LO. A practical classification of newborn infants by weight and gestational age. J Pediatr. 1967;71(2):159-63.

5. Mandruzzato G. Intrauterine restriction (IUGR). J Perinat Med. 2008;36:277-81.

6. Brodsky D, Christou H. Current concept in intrauterine growth resteiction. J int Care Med. 2003;19:307-19.

7. Aucott SW, Donohue PK, Northington FJ. Increased morbidity in severe early intrauterine growth restriction. J Perinatol. 2004;24:435-40.

8. Lapillone A, Peretti N, Ho PS, Claris O, Salle BL. Aetiology, morphology and body composition of infants born small for gestational age. Acta Paediatr Suppl. 1997;423:173-6.

9. Crovetto F, Triunfo S, Crispi F, Rodriguez-Sureda V, Dominguez C, Figueras F, et al. Differential performance of first trimester screening in predicting small for gestational age neonates or fetal growth restriction. Ultrasound Obstet Gynecol. 2016;49:34956.

10. Fowden AL, Forhead AJ. Endocrine mechanisms of intrauterine programming. Repro. 2004;127(5):515-26.

11. Chesley LC. Hypertensive disorders in pregnancy. New York: Appleton-Century- Crofts; 1978.

12. Wu G, Bazer FW, Cudd TA, Meininger CJ, Spencer TE. Maternal nutrition and fetal development. J Nutr. 2004:2169-72.

13. Goldenberg RL, Cutter GR, Hoffman HJ, Foster JM, Nelson KG, Hauth JC. Intrauterine growth 
retardation: Standards for diagnosis. Am J Obstet Gynecol. 1989;161:271-7.

14. World Health Organization. Women's health. Fact sheet $\quad \mathrm{N}^{\circ} 334$. 2013. Available at: http://www.who.int/mediacentre/factsheets/fs334/en. Accessed on $11^{\text {th }}$ July 2017.

15. Sachdeva PD, Patel BG, Bhatt MV. A study of incidence and management of pregnancy induced hypertension in Central Gujarat, India. Int $\mathbf{J}$ Univer Pharma Life Sci. 2011;1(3):61-70.

16. Anna L, Millar S, Lynnae K. To relate hypothyroidism to perinatal outcome. March. 1993;161:271-7.

17. National study on essential obstetric care facilities in Nigeria. Federal Ministry of Health, Abuja, Nigeria. 2003:37.

18. Chauhan SP, Taylor M, Shields D, Parker D, Scardo JA, Magann EF. Intrauterine growth restriction and oligohydramnios among high-risk patients. Am J Perinatol. 2007;24(4):215-21.

19. Lindblad B, Zaman S, Malik A. Vitamin B12, and homocysteine levels in South Asian Women with growth-retarded fetuses. Obstet Gynecol Surv. 2006;61:91-2.

20. Jansson T, Ylven K, Wennergren M, Powell TL. Glucose transport and system a activity in syncytiotrophoblast microvillous and basal plasma membranes in intrauterine growth restriction. Placenta. 2002;23:392-9.

Cite this article as: Sharma V, Shukla N. Prevalence and risk factor for intrauterine growth restriction among pregnancy-induced hypertension patient. Int $\mathbf{J}$ Reprod Contracept Obstet Gynecol 2019;8:3985-90. 